Portellano-Ortiz C, Garre-Olmo J, Calvó-Perxas L, Conde-Sala JL. Factor structure of depressive symptoms using the EURO-D scale in the over-50s in Europe. Findings from the SHARE project. Aging \& Mental Health, 2017, Published online on August 31, 2017 doi: 10.1080/13607863.2017.1370688.

http://www.tandfonline.com/doi/full/10.1080/13607863.2017.1370688

\title{
Factor structure of depressive symptoms using the EURO-D scale in the over-50s in Europe. Findings from the SHARE project
}

Authors: Cristina Portellano-Ortiz ${ }^{\mathrm{a}}$, Josep Garre-Olmob,c, Laia Calvó-Perxas ${ }^{\mathrm{b}}$, Josep Lluís Conde-Sala ${ }^{\mathrm{a}, \mathrm{b}}$

\section{Institutional affiliations}

${ }^{\mathrm{a}}$ Faculty of Psychology, University of Barcelona. Spain

${ }^{\mathrm{b}}$ Girona Biomedical Research Institute (IDIBGI), Research Unit, Institut d'Assistència Sanitària, Salt, Spain

${ }^{\mathrm{c}}$ Department of Medical Sciences, University of Girona, Spain

\section{Conflict of interest: None}

Words. Abstract: 212; text: 4,141; Tables: 5; Figure 1.

Supplementary data (Figure: 1, Table: 1)

\section{Corresponding author:}

Cristina Portellano-Ortiz

Faculty of Psychology. University of Barcelona

Passeig Vall d’Hebron, 171. 08035 Barcelona. Spain

Tel. (+34) 93 3125814; Fax: (+34) 93 4021368; E-mail: cristina.portellano@ub.edu 


\section{ABSTRACT}

Objectives: The aims of this study are: to analyze the factor structure of the EURO-D depression scale; to explore the variables associated with depressive symptoms in the total sample and in the EURO-D factors; and to compare the presence of depressive symptoms and the factor distribution in 15 European countries.

Method: 62,182 participants in Wave 5 (2013) of the Survey of Health, Aging and Retirement in Europe (SHARE) were included. Instruments: The SHARE study and the EURO-D scale. Factor, bivariate and multilevel analyses were performed.

Results: Higher levels of depressive symptoms were associated with a poorer self-perception of physical health $\left(\eta^{2}=0.22\right)$ and economic difficulties $\left(\eta^{2}=0.07\right)$. Factor analysis of the EURO-D identified two factors: Suffering and Motivation. Higher levels of depressive symptoms were associated with female gender and younger age $(\leq 60)$ in the Suffering factor, and with less activity and exercise, older age ( $\geq 71)$, widowhood and lower educational level in the Motivation factor. Poorer self-perception of physical health and economic difficulties were associated with higher depressive symptomatology in both factors.

Conclusions: Poorer self-perception of physical health, female gender, economic difficulties, widowhood, lower levels of activity and exercise and lower educational level were associated with higher depressive symptomatology. In the countries of southern Europe, the Motivation factor predominated.

KEY WORDS: EURO-D, Depressive symptoms, Aging, SHARE, Factor analysis, European countries 


\section{Introduction}

Demographic data show that Europe is characterized by an increasing life expectancy, a low fertility rate, and a large proportion of people over the age of 65 . This situation has fostered a growing interest in the conditions and quality of life of this older age group (Angelini, Cavapozzi, Corazzini, \& Paccagnella, 2012), with a particular emphasis on the study of depression. It is estimated that, by 2020, depression will rise from third to second place among the health problems of old age (Vos et al., 2015).

Depressive disorders in the elderly tend to be associated with functional disabilities and poor physical health (Braam et al., 2005), and are often underdiagnosed and poorly treated. They lead to an increase in the use of health services and medical costs and may also make the elderly more vulnerable to other diseases (Katon, Lin, Russo, \& Unutzer, 2003).

The mean prevalence of clinically relevant depressive syndromes in older people in Europe is $12.6 \%$, although the figures in the various studies range widely from $9.9 \%$ to $32.0 \%$ (Braam et al., 2014). The variability in the reported prevalence is due in part to the diagnostic criteria and instruments used (Beekman, Copeland, \& Prince, 1999), but it has also been attributed to cultural aspects such as feelings of loneliness, which are more present in the countries of southern Europe than in the north (Van Tilburg \& Dykstra, 2008). In addition, several studies have associated this variability with welfare models, economic difficulties and social inequalities, finding poorer socioeconomic conditions and higher levels of depression in the countries of southern and eastern Europe (Ladin, Daniels, \& Kawachi, 2010; Levecque, Van Rossem, De Boyser, Van de Velde, \& Bracke, 2011; Chung et al., 2013).

Research into the socio-demographic variables associated with depression in older people shows that it is more prevalent in women (Aziz \& Steffens, 2013; Calvó-Perxas, VilaltaFranch, Turró-Garriga, López-Pousa, \& Garre-Olmo, 2016). As regards age, the variations are inconsistent, probably because other factors such as physical health, economic difficulties and 
the quality of social networks play a greater part (Blazer, 2003). Depressive symptoms are more common in widows and widowers (Zhang \& Li, 2011; Vable, Subramanian, Rist, \& Glymour, 2015) and in people with a lower level of education (Kok, Avendano, Bago d'Uva, \& Mackenbach, 2012). As far as retirement is concerned, some studies point to an association between better perceptions of health and lower levels of depression (Coe \& Zamarro, 2011; Halleröd, Örestig, \& Stattin, 2013). Lack of physical exercise and activity has also been associated with depression (Lindwall, Larsman, \& Hagger, 2011), as have functional disabilities and the deterioration of physical health (Holahan et al., 2010; Büchtemann, Luppa, Bramesfeld, \& Riedel-Heller, 2012; Deschênes, Burns, \& Schmitz, 2015).

Two of the most frequently used scales for evaluating depression are the CES-D (Radloff, 1977) and the EURO-D (Prince et al., 1999). Performing a factor analysis of the scale, Prince et al (1999) proposed a two-factor solution of Affective Suffering and Motivation. These two factors were confirmed in further research with different names Affective Suffering/Motivation (Castro-Costa et al., 2007, 2008; Guerra, Ferri, Llibre, Prina, \& Prince, 2015), who found a different distribution of factors by country.

However, the clinical and sociodemographic variables associated with the two factors identified in EURO-D, and their predominance in European countries, have not been studied in detail. Therefore, we decided to analyze the depression-related variables commonly found in the literature and the factors of the EURO-D in a large sample of non-institutionalized participants aged over 50 from 15 SHARE countries (Wave 5).

The objectives of this study were: 1) to analyze the factor structure of EURO-D; 2) to investigate the variables associated with depressive symptoms in the total sample and in the resulting EURO-D factors; and 3) to compare the presence of depressive symptoms and the predominance of the factors and the associated variables in 15 European countries. 


\section{Method}

\section{Design and study population}

Cross-sectional study of Wave 5 data (2013) from the Survey of Health, Aging and Retirement in Europe (SHARE). SHARE provides data on the health, socioeconomic status and social and family networks of non-institutionalized individuals over the age of 50 from a variety of European countries and from Israel (Börsch-Supan et al., 2005, 2013). The response rates for eligible households ranged from 64\% in France to 89\% in Estonia, and were between 70-80\% in most countries (Malter \& Börsch-Supan, 2015).

Data from the sample were collected through a computer-assisted personal interview (CAPI) lasting approximately 90 minutes at the participant's home (Börsch-Supan et al., 2013). The countries included in the study were the ones that participated in Wave 5 of SHARE (Estonia, Italy, France, Spain, Belgium, Luxembourg, Czech Rep., Slovenia, Germany, Israel, Austria, Sweden, Netherlands, Switzerland and Denmark). The sample comprised the 62,182 subjects out of the 65,281 initially available in Wave 5 of SHARE, after excluding cases in which information was missing for some of the items on the EURO-D scale.

\section{Variables and instruments}

Socio-demographic data. Age (average and subgroups), gender, marital status, years of schooling, social activities (membership of clubs, training courses, political or community organizations, volunteering), frequency of physical exercise, employment status (employed, retired, homemaker, unemployed, sick and disabled), economic difficulties, and selfperception of physical health.

Depressive symptoms. The instrument used was the EURO-D scale, which consists of 12 dichotomous items indicating the presence or absence (depressive symptoms, pessimism, 
death wish, guilt, irritability, crying, fatigue, sleep problems, loss of interest and appetite, reduced ability to concentrate and capacity to enjoy things over the last month), with a cut-off point for depression of $\geq 4$ (Prince et al., 1999). The total score ranges from 0 to 12 . Higher scores indicate greater presence of depressive symptoms. In the EURODEP study (Guerra et al., 2015) the scale had a moderate Cronbach's alpha (0.61-0.75), as in the present study (0.71). Studies conducted with the data from SHARE (Survey of Health, Ageing and Retirement in Europe) in Wave 2 (2006-07) show a high correlation $(\mathrm{r}=0.68, p<0.000)$ between the 8-item CES-D scale (Kohout, Berkman, Evans \& Cornoni-Huntley, 1993) and the EURO-D, the associations with the risk factors being in the same direction (Courtin, Knapp, Grundy \& Avendano-Pabon, 2015).

\section{Statistical analysis}

A descriptive study of the sample was performed using means and standard deviation for the continuous variables and frequencies for the categorical variables. The bivariate contrasts of the categorical variables were performed using the Chi squared test $\left(\chi^{2}\right)$ and, in the continuous variables, the Student's $t$ test and F ANOVA parametric tests.

To assess the effect size of the difference between two means Cohen's $(d)$ was used, whose values indicate weak (0.2-0.4), moderate (0.5-0.8) or strong (>0.8) effects (Cohen, 1992). The difference between several means was determined with the eta squared $\left(\eta^{2}\right)$, whose values indicate weak (0.01-0.05), moderate $(0.06-0.13)$ or strong $(>0.14)$ effects (Cohen, 1973). The effect size in the contrasts of the categorical variables was evaluated with Cramer's $V$, whose values depend on the degrees of freedom: $\mathrm{df}_{1}=$ small: $\leq 0.10$, medium: 0.11-0.49, large: $\geq 0.50 ; \mathrm{df}_{2}=$ small: $\leq 0.07$, medium: $0.08-0.34$, large: $\geq 0.35 ; \mathrm{df}_{3}=$ small $\leq$ 0.06, medium: 0.07-0.28, large: $\geq 0.29 ; \mathrm{df}_{4}=$ small: $\leq 0.05$, medium: 0.06-0.25, large: $\geq 0.25$. (Cohen, 1988). 
To perform the factor analysis, the sample was randomly divided into two sub-samples of a similar number (30,865 and 31,317). Exploratory analysis was performed in the first subsample and confirmatory analysis in the second. In the exploratory analysis, the principal components extraction method was used and a Varimax rotation was applied, selecting factor loads greater than 0.40 (Floyd \& Widaman, 1995). The exploratory factor analysis of the EURO-D indicated two factors, termed Suffering and Motivation. In the confirmatory factor analysis, since the variables were ordinal the Diagonally Weighted Least Squares method was used to estimate the weight of the factors ( $\mathrm{Li}, 2016)$, indicating the goodness of fit indices.

In order to evaluate the joint influence of the independent variables on the EURO-D and the two factors, a multilevel analysis (Pardo, Ruiz, \& San Martín, 2007) was carried out using four models: the null model (without independent variables), the global EURO-D model, and the models of the variables in each of the two EURO-D factors identified. The intraclass correlation coefficient (ICC) explains the degree of variability between countries.

The total EURO-D scores and the scores on the two factors were analyzed in each country. For the graphical representation of the differences, the raw scores were transformed into $\mathrm{T}$ scores by applying the transformation $\mathrm{T}=10 \mathrm{z}+50$, because the range of each factor was different. Finally, the distribution of socio-demographic and clinical variables was analyzed in the groups of countries with a predominance of the Suffering factor or the Motivation factor.

The level of statistical significance for the contrasts of hypotheses was 0.01 . Statistical analysis was performed using SPSS v22.0 for Windows (SPSS Inc., Chicago). For the confirmatory factor analysis the LISREL v9.2 program (Jöreskog \& Sörbom, 2015). Scientific Software International Inc.) was used. 


\section{Results}

\section{Description of the sample}

The study sample consisted of 62,182 participants with a mean age of $66.8 \pm 9.9$ years. The majority were women (55.6\%), were married (70.4\%), and had more than 8 years of schooling (71.8\%). With regard to the EURO-D, 26.3\% of the participants scored above the cut-off point for depression ( $\geq 4$ ). The overall mean score for depression was $2.40 \pm 2.2$. The complete data are shown in Table 1.

\section{Table 1}

\section{Factor analysis of the EURO-D}

An exploratory factor analysis of the EURO-D was performed to analyze the distribution of the items and the resulting factors (Table 2). A preliminary examination of the correlation matrix (Bartlett sphericity index $p<0.001$ ) and sample adequacy (Kaiser-Meyer-Olkin index 0.837) confirmed the adequacy of the factor analysis which produced two factors termed Suffering and Motivation. The Suffering factor consisted of the following items: depressed mood, guilt, sleep, irritability, fatigue and tearfulness; depressed mood was the item with the highest factor load (0.733). The Motivation factor was composed of the following items: pessimism, interest, lack of appetite, concentration and finally enjoyment, the item with the highest factor load (0.667). The item "suicidality" was not included in either factor because it did not reach the required level of factor load $(\geq 0.40)$.

\section{Table 2}

In the confirmatory factor analysis, with a sample of 31,317 participants, the goodness of fit indices were satisfactory (Batista-Foguet, Coenders, \& Alonso, 2004): Chi square $\chi^{2}=$ 1375.87, $\mathrm{df}=43, p<0.0000$; Not Normed Fit Index $(\mathrm{NNFI})=0.99$; Comparative Fit Index 
$(\mathrm{CFI})=0.99$; Standardized Root Mean Square Residual $($ SRMSR) $=0.043$; Root Mean Square Error of Approximation (RMSEA) = 0.031 (Supplementary data, Figure).

\section{EURO-D: factors and variables. Bivariate analysis}

In the bivariate analysis, the association of each of the variables on the EURO-D is shown in the supplementary table (bivariate analysis, EURO-D, factors and variables). The highest EURO-D scores in the total sample were reported by participants over the age of 80, women, widows/widowers, those with lower educational levels, homemakers, the disabled and those who did not engage in social and physical exercise activities, although the effect size was weak $\left(\eta^{2}=<0.06, d=<0.50\right)$. The variables with the largest effect sizes were economic difficulties $\left(\eta^{2}=0.07\right)$ and, above all, worse self-perception of physical health $\left(\eta^{2}=0.22\right)$.

The largest differences between the factors of Suffering and Motivation regarding the presence of depressive symptoms were observed in women ( $d=0.45$ vs. 0.07 ), which were higher in the Suffering factor. The lack of physical exercise $\left(\eta^{2}=0.06\right.$ vs .0 .02$)$, the lack of social activities ( $d=0.48$ vs. 0.07$)$ and economic difficulties $\left(\eta^{2}=0.06\right.$ vs .04 ) were higher in the Motivation factor. Worse self-perception of physical health was associated with a higher presence of depressive symptoms in both factors, with strong effect sizes ( $\eta^{2}=0.15$ vs .0 .16 ).

\section{EURO-D: factors and variables. Multi-level analysis}

A multilevel analysis was performed in which all the independent variables were introduced together (Table 3). In the null model (without independent variables), the estimated value of the intercept in the fixed effects for the EURO-D was coefficient $=2.32, \mathrm{SE}=0.10, t=22.3$, $p<0.001$. The parameter estimates associated with the random effects were, for the variance of the countries, coefficient $=0.16, \mathrm{SE}=0.06$; Wald $\mathrm{z}=2.6, p=0.009$, and for the residual variance, coefficient $=4.91, \mathrm{SE}=0.02$; Wald $\mathrm{z}=176.3, p<0.001$. These estimates indicated that the inter-country variability was $3 \%($ ICC $=0.16 /[0.16+4.91]=0.03)$. 
In the global EURO-D score, the highest levels of depressive symptoms were associated, in order of relevance, with worse self-perception of physical health, female gender, economic difficulties, unemployment and disability, younger $(\leq 60)$ and older $(\geq 71)$ age, being divorced or widowed, non-participation in activities, lack of physical exercise, and lower educational level.

Some notable differences were observed in relation to the factors. The Suffering factor affected females, the younger age group $(\leq 60)$ and the unemployed more intensely; protective variables were unmarried status, physical exercise and activities and higher level of education. The Motivation factor was more relevant in those who did not perform social activities and physical exercise, in homemakers, in unmarried individuals and in widows/widowers, in the older age group ( $\geq 71$ years) and in those with less than 12 years of schooling; in this factor there were no significant protective variables. Worse self-perception of physical health and economic difficulties were associated with more depressive symptoms in both factors.

Table 3

\section{EURO-D and factor analysis according to country}

The differences between countries in relation to age were small (age range: 64.8 - 68.0), with a weak effect size $\left(\eta^{2}=0.01\right)$. As for gender, the differences were somewhat higher (range of proportions 52.3-61.2\%, Cramer's $V=0.05$ ). On the other hand, differences in education (average years of schooling) were notable, with a moderate effect size $\left(\eta^{2}=0.12\right)$.

The results of the mean EURO-D scores and factors are shown in table 4. The EURO-D scores were above average (> 2.4) in Estonia, Italy, France, Spain, Luxembourg, Belgium and the Czech Republic. As regards the difference between the scores, the Suffering factor scores were higher in all countries; in general effect sizes were strong ( $d=0.82-1.05)$, though only 
moderate in the Mediterranean countries: Slovenia $(d=0.73)$, Italy $(d=0.62)$, Israel $(d=$ $0.58)$ and Spain $(d=0.44)$.

Table 4

Analyzing the relative differences between the factors with the scores $T=10 z+50$, the scores on the Motivation factor were higher $(p<0.001)$ in the Mediterranean countries (Spain, Italy, Israel and Slovenia). In the Netherlands and Austria, the differences were not significant, while in the remaining countries the scores on the Suffering factor were higher (Figure 1).

Figure 1

Table 5 shows the differences in the frequency of variables between the two groups of countries, the ones with the highest significant scores on the Motivation factor (Spain, Italy, Israel and Slovenia), and the highest significant scores on the Suffering factor (Sweden, France, Belgium, Denmark, Czech Republic, Luxembourg, Estonia, Germany and Switzerland). Compared with the countries with a predominance of the Suffering factor, countries with a predominance of the Motivation factor had lower educational levels $(<9$ years: $47.4 \%$ vs 19.6 ), greater economic difficulties (50.6\% vs 28.2 ), lower engagement in social activities (38.2\% vs 62.1), lower distribution of employment (fewer people in work $23.9 \%$ vs 30.6 , more homemakers $16.2 \%$ vs 4.3 and more unemployed $4.2 \%$ vs 2.5 ), marital status (more married 77.5\% vs.67.8 and fewer divorced 4.4\% vs.12.2) and a lower level of exercise (49.7\% vs. 58.9).

Table 5 


\section{Discussion}

\section{Factor analysis of the Euro-D}

The first objective of the study was the analysis of the factor structure of the scale and the variables associated with each factor. Two factors were identified: Suffering, and Motivation. The results are broadly consistent with the original study by Prince et al. (1999) and the studies by Castro-Costa et al. (2007, 2008). The most relevant difference was the absence in our results of the item "suicidality", whereas in Castro-Costa et al.'s studies this item was included in the first factor, Affective Suffering.

\section{Variables associated with the presence of depressive symptoms}

The second objective of the study was to identify the variables associated with the presence of depressive symptoms in older subjects in the total sample. The analysis showed that the variables most strongly related with depression were worse self-perception of physical health and difficulty making ends meet. Our findings replicate those of previous studies which have found associations between depression and poor health (Deschênes et al., 2015) or between depression and financial problems (Levecque et al., 2011; Chung et al., 2013).

As far as gender is concerned, our results indicate that women have more depressive symptoms than men (Calvó-Perxas et al., 2016). Parker \& Brotchie (2010) emphasize the importance of biological factors related to the response to stress. The association between age and mental health is mediated by physical health and living conditions in older people, so that age itself has no explanatory power (Buber \& Engelhardt, 2011). This is consistent with the results of the present study, which found a weak effect size in the overall sample; however, in the literature depressive symptoms are commonly found to be more frequent in older people (Jeste et al., 2013). In our study, lower educational levels were associated with higher levels 
of depression (Kok et al., 2012), especially in southern European countries where there was a predominance of the Motivation factor.

With regard to marital status, divorcees and especially widows/widowers presented more depressive symptoms, as other studies have reported (Vable et al., 2015). Physical inactivity was associated with more depressive symptoms, whereas physical exercise was a protective variable; indeed, the relationship between depression and physical exercise is known to be reciprocal (Lindwall et al., 2011). Finally, the inverse relationship between social activities and depressive symptoms observed in our study is also supported by other research (Katja et al., 2014; Holtfreter, Reisig, \& Turanovic, 2017).

\section{Variables associated with the factors of the EURO-D}

Another aspect related to the second objective was the analysis of the variables associated with each factor. The multilevel analysis showed that worse self-perception of physical health was associated with a higher level of depressive symptoms in both Suffering and Motivation. Female gender and younger age were more relevant in the Suffering factor, while older age, widowhood, lower educational level, non-participation in physical activities and not taking physical exercise were more relevant in the Motivation factor. It could be said that the Motivation factor was associated with greater passivity.

The difference in the weight distribution of the factors in relation to the sociodemographic variables is one of the most interesting findings of the study. The results for gender (Suffering) and older age (Motivation) corroborated those of Castro-Costa et al. (2007).

\section{Depressive symptoms and factor distribution by country}

The third objective of the study was to analyze the presence of depressive symptoms and the distribution of the incidence of the factors in the countries in the sample. The high presence of 
depressive symptoms in France, Spain, Italy and Belgium coincided with previous studies (Castro-Costa et al., 2007; Ladin et al., 2010; Gallagher, Savva, Kenny, \& Lawlor, 2013; Portellano-Ortiz, Garre-Olmo, Calvó-Perxas, \& Conde-Sala 2016).

Interestingly, when assessing the factor distribution of the EURO-D in European countries, we found differences in the distribution of Suffering and Motivation factors. When raw scores were converted into T scores, southern European countries (Spain, Italy, Israel and Slovenia) scored higher on the Motivation factor, while the remaining countries scored higher on the Suffering factor.

These differences highlight the importance of cultural and social aspects in the manifestation of depression. Van Tilburg \& Dykstra (2008) identify three aspects that might explain the differences in rates of depression between countries: individual differences, cultural differences between countries, and the combination of the two. Indeed, our results indicate that cultural aspects such as education, engagement in activities and exercise, economic difficulties, employment and marital status are reflected in the differences in the predominance of EURO-D factors in the various European countries.

This lower educational level, which is relevant in the countries with a predominance of the Motivation factor, has also been associated with higher unemployment rates, economic difficulties, and lower quality of life (Conde-Sala, Portellano-Ortiz, Calvó-Perxas, \& GarreOlmo, 2016).

An important problem in multinational studies is the criteria used by participants from different countries to assess their depressive symptoms. Kok et al. (2012) studied the differences between 10 European countries in the prevalence of three depressive symptoms on the EURO-D (mood, sleep and concentration) and their association with educational level, using HOPIT (Hierarchical Ordered Probit) models to analyze the heterogeneity of the reports and to identify differences in the thresholds reported for depressive symptoms. Controlling for 
the heterogeneity of the reports and using an identical response scale, they observed that differences between countries and educational levels were maintained. They concluded that the differences in the prevalence of depressive symptoms were not explained by differences in the thresholds used, but were probably the result of variations in the causes of the depressive symptoms. Among the factors associated with greater depression were poorer physical health and lower educational and socioeconomic levels, factors that were more frequent in the Mediterranean countries and Eastern Europe.

European social welfare models have also been linked to depression (Whelan \& Maître, 2010). In one study, mean scores for depression were highest in southern and eastern European countries, with interactions between depression and economic difficulties at retirement age that were twice (south) or three times (east) as high as those recorded in younger individuals, highlighting the role of social welfare models in mitigating or even reversing the effects of economic hardship and aging on health (Levecque et al., 2011). In a comparison of seven social welfare regimes, individuals in southern European countries were more likely to experience a depressive episode in the past 12 months (Chung et al., 2013). Likewise, income and social inequalities have been related to depression, with more negative effects in Spain, Italy and Greece (Ladin et al., 2010). Participation in social activities was lower in the southern Europe countries than in the north (south, $7.5 \%$ vs. north, 32.6\%) (Croezen, Avendano, Burdorf, \& van Lenthe, 2015).

Interestingly, in spite of the worse socioeconomic conditions in southern Europe countries, rates of suicide in people> 50 years (WHO, 2014) in countries like Italy and Spain were lower than in 13 other European countries (10.8 vs. 21.0/100,000 inhabitants), (CondeSala et al., 2016). Family support in situations of aging, which is more common in these countries, emerged as a key socio-cultural element in the mental health of the elderly. 


\section{Clinical Implications}

Our results corroborate those of longitudinal studies of SHARE regarding the relationship between major depressive symptoms and low social participation (Croezen et al., 2015) or lack of physical exercise (Lindwall et al., 2011). It would be useful to design interventions that promote social participation and physical exercise, since these variables are related to the appearance of depressive symptoms and are clearly modifiable.

Above all, efforts should also be made to counteract the stereotype of old age as the final stage of life in which people withdraw from public activity, become marginalized and are less and less integrated and engaged in society (Murray \& López, 1997).

\section{Limitations and future research}

One limitation of the study is its cross-sectional design. In future research it would be advisable to use longitudinal data to confirm that the direction of the associations of the variables with participants' depressive symptoms is the same across factors and countries. Another limitation is the need to study in more depth the economic, social and cultural aspects of the different countries in relation to the prevalence of depressive symptoms.

Furthermore, the differences with regard to previous studies in the results for depression in the various age groups suggest the need to examine this aspect in detail.

The interaction between cognitive status and depressive symptoms (Gallagher, Kiss, Lanctot, \& Herrmann, 2016) was not analyzed in this study, but will be addressed in future work. Focusing on participants' life experiences would be another interesting line of research (Crespo, López-Noval, \& Mira, 2014). 


\section{Conclusions}

The factor analysis of EURO-D identified two factors, Suffering and Motivation. In the Suffering factor, major depressive symptoms were associated with female gender and younger age, while in the Motivation factor the associated factors were the lower levels of social activities and physical exercise, older age, widowhood, and lower education. Poor selfperception of physical health and economic difficulties were associated with greater depressive symptomatology in both factors.

In the Mediterranean countries (Spain, Italy, Israel and Slovenia) there was a greater prevalence of the Motivation factor, whereas in some continental countries and in Eastern Europe (Switzerland, Germany, Estonia) the Suffering factor predominated. 


\section{Authors' contributions}

CPO participated in study design, statistical analysis and writing of article. JGO participated in study design, statistical analysis and review of article. LCP participated in study design, statistical analysis and review of article. JLCS participated in study design, statistical analysis and writing of article.

\section{Conflicts of interest}

None

\section{Financial Support}

None

\section{Acknowledgements}

This paper uses data from SHARE Wave 5 release 1.0.0, as of March 31st 2015 (DOI: 10.6103/SHARE.w5.100) The SHARE data collection has been primarily funded by the European Commission through the 5th Framework Programme (project QLK6-CT- 200100360 in the thematic programme Quality of Life), through the 6th Framework Programme (projects SHARE-I3, RII-CT-2006-062193, COMPARE, CIT5- CT-2005- 028857, and SHARELIFE, CIT4-CT-2006-028812) and through the 7th Framework Programme (SHAREPREP, N 211909, SHARE-LEAP, N²27822 and SHARE M4, N²61982). Additional funding from the U.S. National Institute on Aging (U01 AG09740-13S2, P01 AG005842, P01 AG08291, P30 AG12815, R21 AG025169, Y1- AG-4553-01, IAG BSR06-11 and OGHA 04064) and the German Ministry of Education and Research as well as from various national sources is gratefully acknowledged (see www.share-project.org for a full list of funding institutions). 


\section{References}

Angelini, V., Cavapozzi, D., Corazzini, L., \& Paccagnella, O. (2012). Age, Health and life satisfaction among older Europeans. Social Indicators Research, 105(2), 293-308. doi: 10.1007/s11205-011-9882-X

Aziz, R., \& Steffens, D.C. (2013). What Are the Causes of Late-Life Depression? The Psychiatric Clinics of North America, 36(4), 497-516. doi: 10.1016/j.psc.2013.08.001

Batista-Foguet, J.M., Coenders, G., \& Alonso, J. (2004). Confirmatory factor analysis. Its role on the validation of health related questionnaires. Medicina Clinica (Barc.), 122(Suppl 1), 21-27.

Beekman, A.T., Copeland, J.R., \& Prince, M.J. (1999). Review of the community prevalence of depression in later life. British Journal of Psychiatry, 174, 307-311. doi: 10.1192/bjp.174.4.307

Blazer, D.G. (2003). Depression in late life: review and commentary. The journals of gerontology. Series A, Biological Sciences and Medical Sciences, 58(3), 249-265. doi: 10.1176/foc.7.1.foc118

Börsch-Supan, A., Brugiavini, A., Jurges, H., Mackenbach, J., Siegrist, J., \& Weber, G. (2005). Health ageing and retirement in Europe: First results from the survey of health, ageing and retirement in Europe. Mannheim Research Institute for the Economics of Aging (MEA), Mannheim.

Börsch-Supan, A., Brandt, M., Hunkler, C., Kneip, T., Korbmacher, J., Malter, F., ... Zuber, S. (2013). Data Resource Profile: the Survey of Health, Ageing and Retirement in Europe (SHARE). International Journal of Epidemiology, 42(4), 992-1001.

doi: 10.1093/ije/dyt088 
Braam, A.W., Prince, M.J., Beekman, A.T., Delespaul, P., Dewey, M.E., Geerlings, S.W., ... Copelan, J.R. (2005). Physical health and depressive symptoms in older Europeans. Results from EURODEP. British Journal of Psychiatry, 187, 35-42. doi: 10.1192/bjp.187.1.35

Braam, A.W., Copeland, J.R., Delespaul, P.A., Beekman, A.T., Como, A., Dewey, M., ... Skoog, I. (2014). Depression, subthreshold depression and comorbid anxiety symptoms in older Europeans: results from the EURODEP concerted action. Journal of Affective Disorders, 155, 266-272. doi: 10.1016/j.jad.2013.11.011

Buber, I., \& Engelhardt, H. (2011). The association between the age and depressive symptoms among older men and women in Europe. Findings from SHARE. Comparative Population Studies, 36(1), 103-105.

Büchtemann, D., Luppa, M., Bramesfeld, A., \& Riedel-Heller, S. (2012). Incidence of latelife depression: a systematic review. Journal of Affective Disorders, 142(1-3), 172-179. doi: 10.1016/j.jad.2012.05.010

Calvó-Perxas, L., Vilalta-Franch, J., Turró-Garriga, O., López-Pousa, S., \& Garre-Olmo, J. (2016). Gender differences in depression and pain: A two year follow-up study of the Survey of Health, Ageing and Retirement in Europe. Journal of Affective Disorders, 193, 157-164. doi: 10.1016/j.jad.2015.12.034

Castro-Costa, E., Dewey, M., Stewart, R., Banerjee, S., Huppert, F., Mendonca-Lima, C., ... Prince, M. (2007). Prevalence of depressive symptoms and syndromes in later life in ten European countries: the SHARE study. British Journal of Psychiatry, 191, 393-401. doi: 10.1192/bjp.bp.107.036772

Castro-Costa, E., Dewey, M., Stewart, R., Banerjee, S., Huppert, F., Mendonca-Lima, C., ... Prince, M. (2008). Ascertaining late-life depressive symptoms in Europe: an evaluation 
of the Survey version of the EURO-D scale in 10 nations. The SHARE project. International Journal of Methods in Psychiatric Research, 17(1), 12-29. doi: 10.1002/mpr.236

Chung, H., Ng, E., Ibrahim, S., Karlsson, B., Benach, J., Espelt, A., \& Muntaner, C. (2013). Welfare state regimes, gender, and depression: a multilevel analysis of middle and high income countries. International Journal of Environmental Research and Public Health, 10(4), 1324-1341. doi: 10.3390/ijerph10041324

Coe, N.B., \& Zamarro, G. (2011). Retirement effects on health in Europe. Journal of Health Economy, 30(1), 77-86. doi: 10.1016/j.jhealeco.2010.11.002

Cohen, J. (1973). Eta-squared and partial eta-squared in fixed factor ANOVA designs. Educational and Psychological Measurement, 33(1), 107-112. doi: 10.1177/001316447303300111

Cohen, J. (1988). Statistical Power Analysis for the Behavioral Sciences, 2nd ed. Lawrence Erlbaum, Hillsdale New York.

Cohen, J. (1992). A power primer. Psychological Bulletin, 112(1), 155-159.

Conde-Sala, J.L., Portellano-Ortiz, C., Calvó-Perxas, L., \& Garre-Olmo, J. (2016). Quality of life in people aged 65+ in Europe: associated factors and models of social welfareanalysis of data from the SHARE project (Wave 5). Quality of Life Research, 26(4), 1059-1070. doi: 10.1007/s11136-016-1436-X.

Courtin, E., Knapp, M., Grundy, E., \& Avendano-Pabon, M. (2015). Are different measures of depressive symptoms in old age comparable? An analysis of the CES-D and Euro-D scales in 13 countries. International Journal of Methods in Psychiatric Research, 24(4):287-304. doi: 10.1002/mpr.1489. 
Crespo, L., López-Noval, B., \& Mira, P. (2014). Compulsory schooling, educations, depression and memory: New evidence from SHARELIFE. Economics of Education Review, 43, 36-46. doi: 10.1016/j.econedurev.2014.09.003

Croezen, S., Avendano, M., Burdorf, A., \& van Lenthe, F.J. (2015). Social participation and depression in old age: a fixed-effects analysis in 10 European countries. American Journal of Epidemiology, 182(2), 168-176. doi: 10.1093/aje/kwv015

Deschênes, S.S., Burns, R.J., \& Schmitz, N. (2015). Associations between depression, chronic physical health conditions, and disability in a community sample: A focus on the persistence of depression. Journal of Affective Disorders, 179, 6-13.

doi: 10.1016/j.jad.2015.03.020

Floyd, F.J., \& Widaman, K.F. (1995). Factor Analysis in the Development and Refinement of Clinical Assessment Instruments. Pyschological Assessment, 7(3), 286-299. doi: 10.1037/1040-3590.7.3.286

Gallagher, D., Savva, G.M., Kenny, R., \& Lawlor, B.A. (2013). What predicts persistent depression in older adults across Europe? Utility of clinical and neuropsychological predictors from the SHARE study. Journal of Affective Disorders, 147(1-3), 192-197. doi: 10.1016/j.jad.2012.10.037

Gallagher, D., Kiss, A., Lanctot, K., \& Herrmann, N. (2016). Depressive symptoms and cognitive decline: A longitudinal analysis of potentially modifiable risk factors in community dwelling older adults. Journal of Affective Disorders, 190, 235-240. doi: 10.1016/j.jad.2015.09.046

Guerra, M., Ferri, C., Llibre, J., Prina, A.M., \& Prince, M. (2015). Psychometric properties of EURO-D, a geriatric depression scale: a cross-cultural validation study. BMC Psychiatry, 15, 12. doi: 10.1186/s12888-015-0390-4 
Halleröd, B., Örestig, J., \& Stattin, M. (2013). Leaving the labour market: the impact of exit routes from employment to retirement on health and wellbeing in old age. European Journal of Ageing, 10(1), 25-35. doi: 10.1007/s10433-012-0250-8

Holahan, C.J., Pahl, S.A., Cronkite, R.C., Holahan, C.K., North, R.J., \& Moos, R.H. (2010). Depression and vulnerability to incident physical illness across 10 years. Journal of Affective Disorders, 123(1-3), 222-229.

Holtfreter, K., Reisig, M.D., \& Turanovic, J.J. (2017). Depression and infrequent participation in social activities among older adults: the moderating role of high-quality familial ties. Aging \& Mental Health, 21(4), 379-388. doi: 10.1080/13607863.2015.1099036

Jeste, D.V., Savla, G.N., Thomson, W.K., Vahia, I.V., Glorioso, D.K., Martin, A.S., ... Depp, C.A. (2013). Association between older age and more successful aging: critical role of resilience and depression. American Journal of Psychiatry, 170(2), 188-196. doi: 10.1176/appi.ajp.2012.12030386

Katja, P., Timo, T., Taina, R., \& Tiina-Mari, L. (2014). Do mobility, cognitive functioning, and depressive symptoms mediate the association between social activity and mortality risk among older men and women? European Journal of Ageing, 11(2), 121-130. doi: 10.1007/s10433-013-0295-3

Katon, W.J., Lin, W., Russo, J., \& Unutzer, J. (2003). Increased medical costs of a population-based sample of depressed elderly patients. Archives of General Psychiatry, 60(9), 897-903. doi: 10.1001/archpsyc.60.9.897

Kohout, F.J., Berkman, L.F., Evans, D.A., \& Cornoni-Huntley, J. (1993). Two shorter forms of the CES-D (Center for Epidemiological Studies Depression) depression symptoms index. Journal of Aging and Health, 5(2), 179-193. doi: 10.1177/089826439300500202 
Kok, R., Avendano, M., Bago d'Uva, T., \& Mackenbach, J. (2012). Can Reporting Heterogeneity Explain Differences in Depressive Symptoms Across Europe? Social Indicators Research, 105(2), 191-210. doi: 10.1007/s11205-011-9877-7

Ladin, K., Daniels, N., \& Kawachi, I. (2010). Exploring the relationship between absolute and relative position and late-life depression: evidence from 10 European countries. Gerontologist, 50(1), 48-59. doi: 10.1093/geront/gnp065

Levecque, K., Van Rossem, R., De Boyser, K., Van de Velde, S., \& Bracke, P. (2011). Economic hardship and depression across the life course: the impact of welfare state regimes. Journal of Health and Social Behavior, 52(2), 262-276.

doi: 10.1177/0022146510394861

Li, C.H. (2016). Confirmatory factor analysis with ordinal data: Comparing robust maximum likelihood and diagonally weighted least squares. Behavior Research Methods, 48(3), 936-949. doi: 10.3758/s13428-015-0619-7

Lindwall, M., Larsman, P., \& Hagger, M.S. (2011). The reciprocal relationship between physical activity and depression in older European adults: a prospective cross-lagged panel design using SHARE data. Health Psychology, 30(4), 453-462.

doi: $10.1037 / \mathrm{a} 0023268$

Malter, F., \& Börsch-Supan, A. (2015). SHARE Wave 5: Innovations \& Methodology. MEA, Max Planck Institute for Social Law and Social Policy, Munich.

Murray, C.J., \& López, A.D. (1997). Global mortality, disability, and the contribution of risk factors: Global burden of disease study. Lancet, 349(9063), 1436-1442. doi: 10.1016/S0140-6736(96)07495-8

Pardo, A., Ruiz, M.A., \& San Martín, R. (2007). Cómo ajustar e interpretar modelos multinivel con SPSS. Psicothema, 19 (2), 308-321. 
Parker, G., \& Brotchie, H. (2010). Gender differences in depression. International Review of Psychiatry, 22(5), 429-436. doi: 10.3109/09540261.2010.492391

Portellano-Ortiz, C., Garre-Olmo, J., Calvó-Perxas, L., \& Conde-Sala, J.L. (2016). Symptoms of depression and associated factors in persons aged 50 and over in Europe and Israel: analysis of data from the SHARE project. International Journal of Geriatric Psychiatry, 31(11), 1250-1251. doi: 10.1002/gps.4467

Prince, M.J., Reischies, F., Beekman, A.T., Fuhrer, R., Jonker, C., Kivela, S.L., ... Copeland, J.R. (1999). Development of the EURO-D scale - a European Union initiative to compare symptoms of depression in 14 European centres. British Journal of Psychiatry, 174, 330338. doi: 10.1192/bjp.174.4.330

Radloff, L.S. (1977). The CES-D scale. A self-report depression scale for research in the general population. Applied Psychological Measurement, 1 (3), 385-401. doi: $10.1177 / 014662167700100306$

Vable, A.M., Subramanian, S.V., Rist, P.M., \& Glymour, M.M. (2015). Does the “widowhood effect” precede spousal bereavement? Results from a nationally representative sample of older adults. American Journal of Geriatric Psychiatry, 23(3), 283-292. doi: 10.1016/j.jagp.2014.05.004

Van Tilburg, T.G., \& Dykstra, P.A. (2008). Differences in older adult's loneliness and depression across Europe. In: Dykstra, P.A. (Ed.), Ageing, intergenerational solidarity and age-specific vulnerabilities NIDI, The Hague, pp. 141-153.

Vos, T., and Global Burden of Disease Study 2013 Collaborators. (2015). Global, regional, and national incidence, prevalence, and years lived with disability for 301 acute and chronic diseases and injuries in 188 countries, 1990-2013: a systematic analysis for the Global Burden of Disease Study 2013. Lancet, 386(9995), 743-800. doi: 10.1016/S01406736(15)60692-4 
Whelan, C.T., \& Maître, B. (2010). Welfare regime and social class variation in poverty and economic vulnerability in Europe: An analysis of EU-SILC. Journal of European Social Policy, 20(4), 316-332. doi: 10.1177/0958928710374378

World Health Organization (WHO). (2014). Preventing suicide: a global imperative. WHO, Geneva, pp. 80-87. http://apps.who.int/iris/bitstream/10665/131056/1/ 9789241564779 _eng.pdf (accessed 20.12.15).

Zhang, B., \& Li, J. (2011). Gender and marital status differences in depressive symptoms among elderly adults: the roles of family support and friend support. Aging and mental health, 15(7), 844-854. doi: 10.1080/13607863.2011.569481 
Table 1. Socio-demographic and clinical variables, $n=62,182$

\begin{tabular}{|c|c|c|c|}
\hline \multicolumn{2}{|l|}{ Age } & \multicolumn{2}{|l|}{ Exercise level, \% } \\
\hline Mean (SD) & $66.89(9.9)$ & More than once a week & 35.3 \\
\hline \multirow[t]{2}{*}{ Range } & 50-104 & Once a week & 13.8 \\
\hline & & 1 to 3 times a month & 8.4 \\
\hline Age, groups, \% & & Hardly ever, or never & 42.5 \\
\hline$\geq 60$ years & 29.0 & & \\
\hline $61-70$ years & 35.0 & Employment status, \% & \\
\hline 71- 80 years & 24.3 & Retired & 57.5 \\
\hline \multirow[t]{2}{*}{$>80$ years } & 11.7 & Working & 28.1 \\
\hline & & Homemakers & 8.0 \\
\hline Gender, \% & & Sick or disabled & 3.5 \\
\hline Male & 44.4 & Unemployed & 2.9 \\
\hline \multirow[t]{2}{*}{ Female } & 55.6 & & \\
\hline & & Making ends meet & \\
\hline Marital status, \% & & Easily & 38.1 \\
\hline Married & 70.4 & Fairly easily & 29.6 \\
\hline Widowed & 13.9 & Some difficulty & 23.8 \\
\hline Divorced & 10.1 & Great difficulty & 8.5 \\
\hline \multirow[t]{2}{*}{ Never married } & 5.6 & & \\
\hline & & Physical health, \% & \\
\hline Schooling, groups, \% & & Very good & 26.0 \\
\hline$>12$ years & 35.6 & Good & 36.9 \\
\hline $9-12$ years & 36.2 & Fair & 27.1 \\
\hline $6-8$ years & 17.0 & Poor & 10.0 \\
\hline $0-5$ years & 11.2 & & \\
\hline \multirow[t]{2}{*}{ Mean (SD) } & $11.0(4.4)$ & EURO-D, Mean (SD) & $2.4(2.2)$ \\
\hline & & $\geq 4$ points, $\%$ & 26.3 \\
\hline \multicolumn{4}{|l|}{ Social activities, \% } \\
\hline Yes & 57.6 & & \\
\hline No & 42.4 & & \\
\hline
\end{tabular}

EURO-D = Depression scale. 
Table 2. Principal components analysis (Varimax rotation) factor loadings for the EURO-D scale

Factor loadings

\begin{tabular}{lrc}
\cline { 2 - 3 } EURO-D items & I (Suffering) & II (Motivation) \\
\hline 1. Depression & $\mathbf{0 . 7 3 3}$ & 0.134 \\
2. Pessimism & -0.003 & $\mathbf{0 . 6 1 6}$ \\
3. Suicidality & 0.367 & 0.363 \\
4. Guilt & $\mathbf{0 . 4 4 5}$ & 0.042 \\
5. Sleep & $\mathbf{0 . 5 4 8}$ & 0.123 \\
6. Interest & 0.209 & $\mathbf{0 . 6 0 0}$ \\
7. Irritability & $\mathbf{0 . 5 6 8}$ & 0.077 \\
8. Low appetite & 0.249 & $\mathbf{0 . 4 1 3}$ \\
9. Fatigue & $\mathbf{0 . 4 8 0}$ & 0.314 \\
10. Concentration & 0.180 & $\mathbf{0 . 5 4 9}$ \\
11. Enjoyment & -0.049 & $\mathbf{0 . 6 6 7}$ \\
12. Tearfulness & $\mathbf{0 . 6 2 0}$ & 0.059 \\
Eigenvalue & 2.945 & 1.234 \\
\hline
\end{tabular}

$n=30,865$

Kaiser-Meyer-Olkin $(\mathrm{KMO})=0.837$

Bartlett's sphericity, Chi-square $=38932.8, p<0.001$

$d f=66$

Note: EURO-D = Depression scale. Items associated with each factor, in bold.

Suicidality was not included in any factor due to not reaching the required level: 0.40. 
Table 3. Multilevel analysis: Parameter estimates in European countries

\begin{tabular}{|c|c|c|c|c|c|c|}
\hline \multirow[b]{2}{*}{ Fixed effects (Ref.) } & \multicolumn{2}{|l|}{ Euro-D } & \multicolumn{2}{|c|}{ Factor 1 (Suffering) } & \multicolumn{2}{|c|}{ Factor 2 (Motivation) } \\
\hline & Coeff.(SE) & $t$ & Coeff. (SE) & $t$ & Coeff. (SE) & $t$ \\
\hline Intercept & $0.70(0.06)$ & $10.5 * * *$ & $0.61(0.05)$ & $12.2 * * *$ & $0.10 \quad(0.03)$ & $3.4^{* *}$ \\
\hline \multicolumn{7}{|c|}{ Physical Health (Very good) } \\
\hline Good & $0.45(0.02)$ & $21.8 * * *$ & $0.39(0.01)$ & $25.8 * * *$ & $0.05 \quad(0.00)$ & $5.9 * * *$ \\
\hline Fair & $1.45(0.02)$ & $60.2 * * *$ & $1.08(0.01)$ & $61.1 * * *$ & $0.31 \quad(0.01)$ & $29.8 * * *$ \\
\hline Poor & $3.01(0.03)$ & $89.0 * * *$ & $1.85(0.02)$ & $74.4 * * *$ & $0.97 \quad(0.01)$ & $64.9 * * *$ \\
\hline \multicolumn{7}{|l|}{ Gender (Male) } \\
\hline Female & $0.64(0.01)$ & $38.1 * * *$ & $0.62(0.01)$ & $50.6 * * *$ & $-0.00 \quad(0.00)$ & -0.2 \\
\hline \multicolumn{7}{|c|}{ Making ends meet (Easily) } \\
\hline Fairly easily & $0.07(0.02)$ & $3.9 * * *$ & $0.04(0.01)$ & $2.8 * *$ & $0.03 \quad(0.00)$ & $4.0 * * *$ \\
\hline Some difficulty & $0.41(0.02)$ & $18.2 * * *$ & $0.27(0.01)$ & $16.4 * * *$ & $0.12(0.01)$ & $12.0 * * *$ \\
\hline Great difficulty & $0.99(0.03)$ & $29.6 * * *$ & $0.59(0.02)$ & $24.3 * * *$ & $0.33 \quad(0.01)$ & $22.4 * * *$ \\
\hline \multicolumn{7}{|l|}{ Employment (Working) } \\
\hline Retired & $-0.03(0.02)$ & -1.4 & $-0.03(0.01)$ & $-1.9 *$ & $-0.00 \quad(0.01)$ & -0.3 \\
\hline Homemakers & $0.05(0.03)$ & 1.3 & $0.00(0.02)$ & 0.1 & $0.04 \quad(0.01)$ & $2.6 * * *$ \\
\hline Unemployed & $0.23(0.04)$ & $4.8 * * *$ & $0.17(0.03)$ & $4.8 * * *$ & $0.03 \quad(0.02)$ & 1.7 \\
\hline Sick or disabled & $0.49(0.04)$ & $10.5 * * *$ & $0.28(0.03)$ & $8.2 * * *$ & $0.16 \quad(0.02)$ & $8.0 * * *$ \\
\hline \multicolumn{7}{|l|}{ Age (61-70) } \\
\hline $71-80$ & $0.05(0.02)$ & $2.6 * *$ & $0.00(0.02)$ & 0.4 & $0.04 \quad(0.00)$ & $5.0 * * *$ \\
\hline$\leq 60$ & $0.14(0.02)$ & $5.9 * * *$ & $0.13(0.01)$ & $7.4 * * *$ & $0.00 \quad(0.01)$ & 0.6 \\
\hline$>80$ & $0.27(0.03)$ & $9.2 * * *$ & $0.00(0.02)$ & 0.3 & $0.25 \quad(0.01)$ & $18.8 * * *$ \\
\hline \multicolumn{7}{|l|}{ Marital status (Married) } \\
\hline Never married & $0.01(0.03)$ & 0.5 & $-0.08(0.02)$ & $-3.2 * *$ & $0.08 \quad(0.01)$ & $5.6 * * *$ \\
\hline Divorced & $0.15(0.02)$ & $5.9 * * *$ & $0.07 \quad(0.01)$ & $4.0 * * *$ & $0.05 \quad(0.01)$ & $4.2 * * *$ \\
\hline Widowed & $0.22(0.02)$ & $8.5 * * *$ & $0.05(0.01)$ & $3.0 * *$ & $0.12(0.01)$ & $10.5 * * *$ \\
\hline \multicolumn{7}{|l|}{ Exercise (More 1 a week) } \\
\hline 1 a week & $-0.11(0.02)$ & $-4.6 * * *$ & $-0.08(0.01)$ & $-4.8 * * *$ & $-0.01 \quad(0.01)$ & -1.6 \\
\hline $1-3$ a month & $-0.03(0.03)$ & -1.0 & $-0.02(0.02)$ & -0.9 & $-0.01 \quad(0.01)$ & -0.7 \\
\hline Hardly never & $0.16(0.01)$ & $8.3 * * *$ & $0.04(0.01)$ & $2.7 * *$ & $0.11(0.00)$ & $13.3 * * *$ \\
\hline \multicolumn{7}{|l|}{ Social Activities (Yes) } \\
\hline No & $0.12(0.01)$ & $7.3 * * *$ & $-0.04(0.01)$ & $-3.5 * * *$ & $0.16 \quad(0.00)$ & $21.0 * * *$ \\
\hline \multicolumn{7}{|l|}{ Schooling (> 12 years) } \\
\hline $9-12$ & $-0.05(0.01)$ & $-2.6 * *$ & $-0.07(0.01)$ & $-5.3 * * *$ & $0.02 \quad(0.00)$ & $2.8 * * *$ \\
\hline $6-8$ & $0.03(0.02)$ & 1.5 & $-0.06(0.01)$ & $-3.3 * *$ & $0.09 \quad(0.01)$ & $8.0 * * *$ \\
\hline $0-5$ & $0.12(0.03)$ & $4.0 * * *$ & $-0.05(0.02)$ & $-2.2 *$ & $0.17 \quad(0.01)$ & $12.8 * * *$ \\
\hline Random effects & Countries & & Countries & & Counties & \\
\hline Covariance parameters & & & & & & \\
\hline $\begin{array}{l}\text { Residual }^{1} \\
\text { Variance (country) }{ }^{1}\end{array}$ & $3.54 \quad(0.02)$ & $169.7 * * *$ & $1.91(0.01)$ & $169.7 * * *$ & $0.70 \quad(0.00)$ & $169.7^{* * *}$ \\
\hline $\begin{array}{l}\text { Variance (country) } \\
\text { ICC }\end{array}$ & $\begin{array}{ll}0.05 & (0.02) \\
0.01 & \end{array}$ & $2.5 *$ & $0.03 \quad(0.01)$ & $2.5 *$ & $\begin{array}{ll}0.01 \quad(0.00) \\
0.01\end{array}$ & $2.5^{* *}$ \\
\hline
\end{tabular}

Note: Dependent variable $=$ EURO-D $($ Depression). In bold the most relevant differential factors.

Coeff. = Estimated parameter, fixed effects; SE = Standard error; ${ }^{1}$ Wald z; ICC = Intraclass correlation coefficient

${ }^{*} p<0.05,{ }^{* *} p<0.01,{ }^{* * *} p<0.001$. 
Table 4. EURO-D and Factors by countries

\begin{tabular}{|c|c|c|c|c|c|c|c|c|}
\hline & \multirow[b]{2}{*}{$n$} & \multicolumn{2}{|l|}{ EURO-D } & \multirow{2}{*}{$\frac{\text { Factor } 1}{\text { Mean (SD) }}$} & \multirow{2}{*}{$\frac{\text { Factor } 2}{\text { Mean (SD) }}$} & \multicolumn{3}{|c|}{ Differences 1-2 } \\
\hline & & $\overline{\text { Mean (SD) }}$ & $\geq 4, \%$ & & & $t$ & $p$ & $d$ \\
\hline Estonia & 5,420 & 3.03 (2.3) & 36.9 & 2.18 (1.5) & $0.77(1.0)$ & 65.9 & $<0.001$ & 1.04 \\
\hline Italy & 4,494 & 2.99 (2.5) & 35.5 & 1.93 (1.6) & $1.01(1.2)$ & 40.2 & $<0.001$ & 0.62 \\
\hline France & 4,272 & $2.82(2.2)$ & 34.2 & 1.95 (1.5) & $0.73(0.9)$ & 51.2 & $<0.001$ & 0.93 \\
\hline Spain & 6,006 & $2.57(2.6)$ & 29.8 & 1.57 (1.6) & $0.92(1.2)$ & 35.2 & $<0.001$ & 0.44 \\
\hline Belgium & 5,409 & $2.55(2.2)$ & 29.2 & $1.81(1.6)$ & $0.63(0.9)$ & 56.0 & $<0.001$ & 0.90 \\
\hline Luxembourg & 1,568 & $2.56(2.2)$ & 28.1 & $1.86(1.6)$ & $0.61(0.9)$ & 31.8 & $<0.001$ & 0.94 \\
\hline Czech Rep. & 5,403 & $2.46(2.2)$ & 26.5 & $1.78(1.5)$ & 0.57 (0.9) & 61.2 & $<0.001$ & 0.93 \\
\hline Slovenia & 2,755 & 2.39 (2.0) & 24.8 & $1.62(1.5)$ & 0.70 (0.9) & 31.1 & $<0.001$ & 0.73 \\
\hline Germany & 5,438 & $2.34(2.0)$ & 24.5 & $1.78(1.5)$ & $0.49(0.8)$ & 63.9 & $<0.001$ & 1.05 \\
\hline Israel & 2,066 & $2.20(2.4)$ & 24.2 & 1.47 (1.6) & $0.67(1.0)$ & 25.8 & $<0.001$ & 0.58 \\
\hline Austria & 3,988 & $1.92(2.0)$ & 19.4 & $1.43(1.4)$ & $0.44(0.7)$ & 44.0 & $<0.001$ & 0.83 \\
\hline Sweden & 4,414 & 1.99 (1.8) & 19.2 & 1.49 (1.4) & $0.45(0.7)$ & 48.8 & $<0.001$ & 0.91 \\
\hline Netherlands & 4,014 & 1.88 (1.9) & 18.1 & 1.39 (1.4) & $0.44(0.7)$ & 43.9 & $<0.001$ & 0.82 \\
\hline Switzerland & 2,942 & 1.89 (1.7) & 17.7 & $1.52(1.4)$ & $0.31(0.6)$ & 45.5 & $<0.001$ & 1.08 \\
\hline Denmark & 3,993 & $1.78(1.8)$ & 17.3 & $1.41(1.4)$ & $0.33(0.6)$ & 48.0 & $<0.001$ & 0.93 \\
\hline Total & 62,182 & $2.40(2.2)$ & 26.3 & $1.70(1.5)$ & $0.62(0.9)$ & \multirow{2}{*}{\multicolumn{2}{|c|}{$180.4<0.001$}} & 0.87 \\
\hline$F, p, \eta^{2}$ & & \multicolumn{2}{|c|}{$<0.001,0.03$} & $<0.001,0.02$ & $<0.001,0.04$ & & & \\
\hline
\end{tabular}

Note: $F$ (Anova); $\eta^{2}=$ Eta-squared; $t=$ Student's $t$ test; $d=$ Cohen's $d$.

EURO-D = Depression scale, Factor 1 (Suffering) and Factor 2 (Motivation). 
Table 5. Differences in the frequency of variables in European countries, according to the predominance of the EURO-D factors

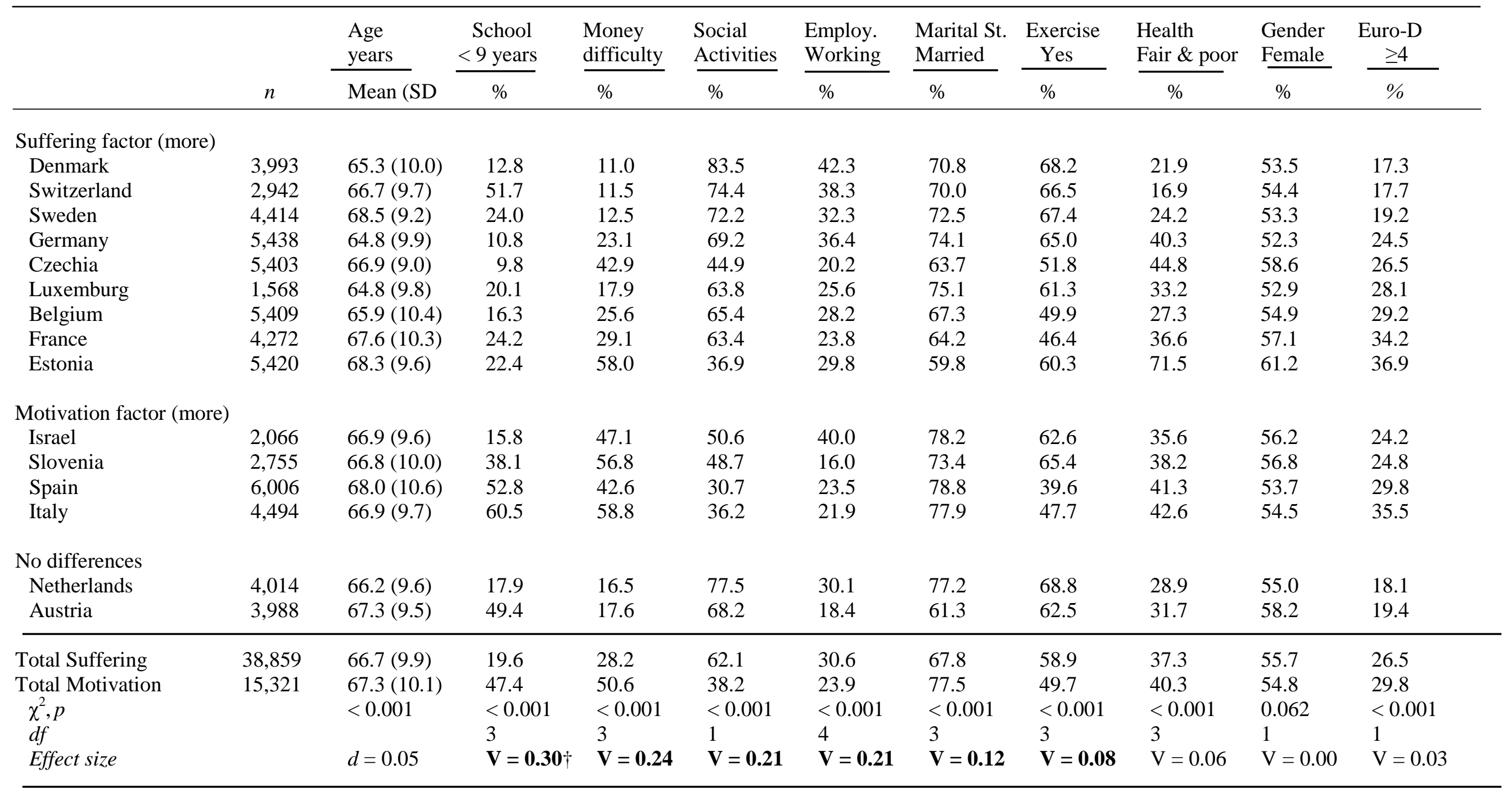

Note: In the variables with several categories (Table 1 , $\mathrm{df}<1$ ) the most relevant is shown.

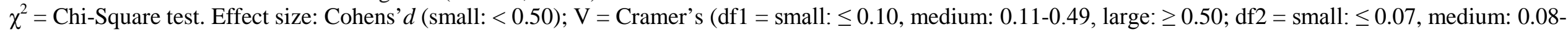

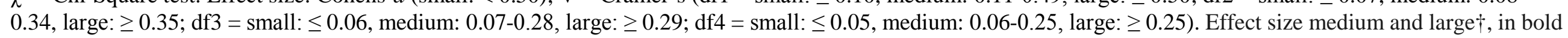


Differences between Suffering and Motivation factors in European countries

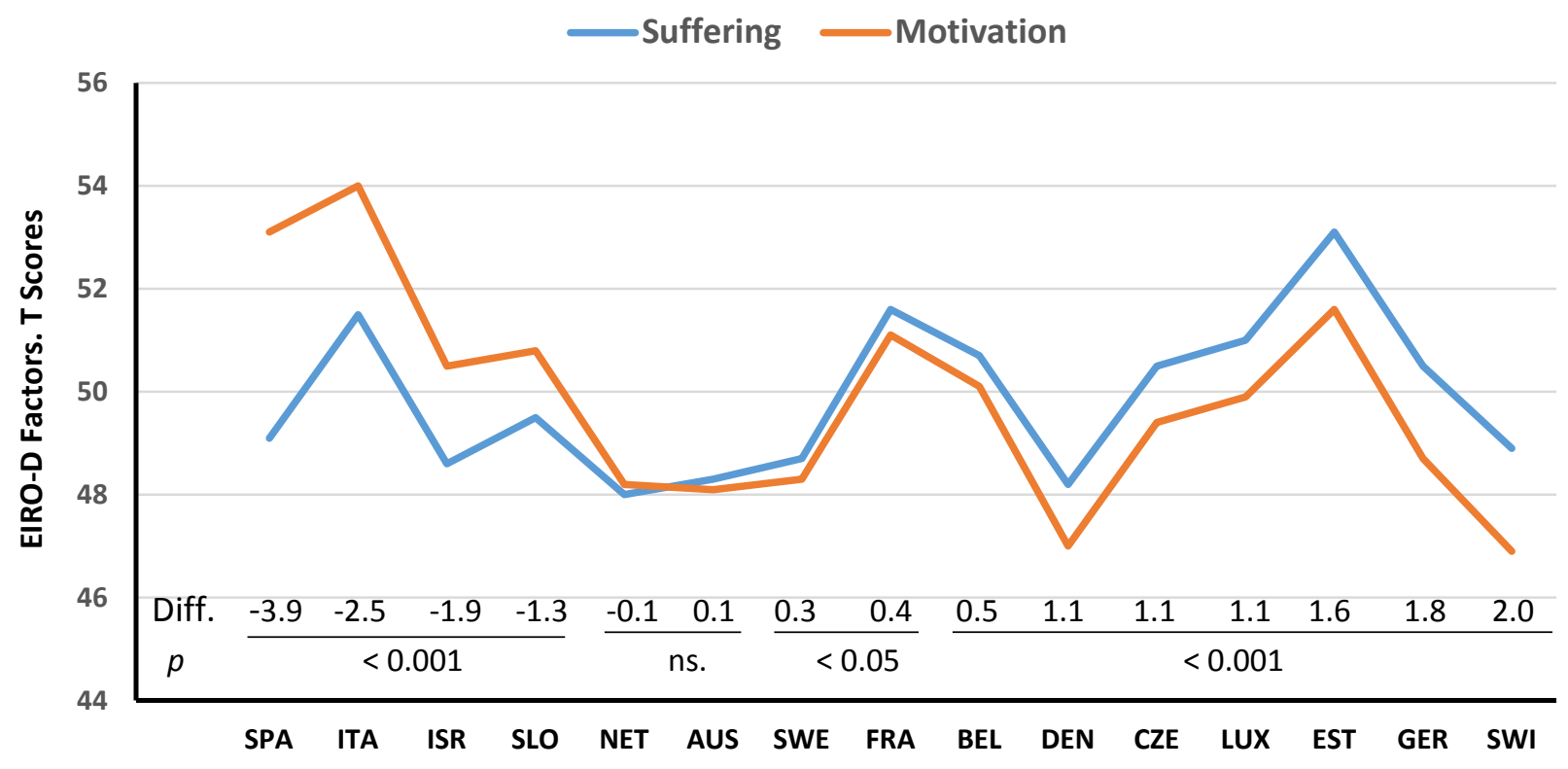

Figure 1. EURO-D (Depression) and factors in European countries 


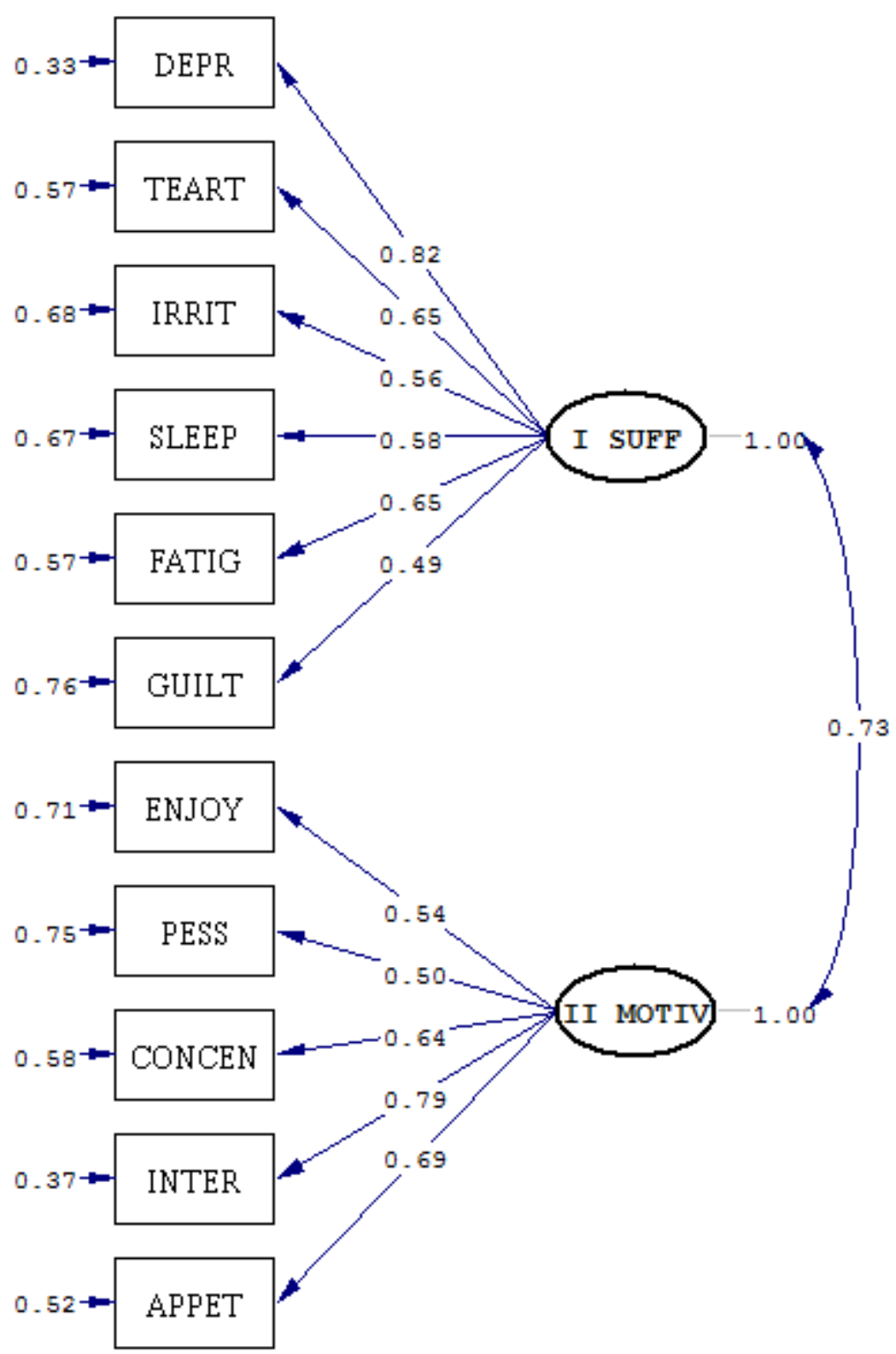

Chi-Square $=1375.87, d f=43, \mathrm{P}-$ value $=0.00000, \mathrm{RMSEA}=0.031$

Supplementary data, Figure. Confirmatory factor analysis of EURO-D 
Supplementary data. Table. Bivariate analysis. EURO-D, Factors and variables

\begin{tabular}{|c|c|c|c|}
\hline & $\begin{array}{l}\text { EURO-D } \\
\text { Mean (SD) }\end{array}$ & $\begin{array}{l}\text { Factor } 1 \\
\text { Mean (SD) }\end{array}$ & $\begin{array}{l}\text { Factor } 2 \\
\text { Mean (SD) }\end{array}$ \\
\hline \multicolumn{4}{|l|}{ Age, group } \\
\hline 1. $\leq 60$ years & $2.26(2.18)$ & $1.71(1.62)$ & $0.48(0.82)$ \\
\hline 2. 61 - 70 years & $2.13(2.09)^{\mathrm{a}}$ & $1.56(1.53)^{\mathrm{a}}$ & $0.50(0.83)$ \\
\hline 3. 71 - 80 years & $2.53(2.29)^{b, d}$ & $1.75(1.55)^{\mathrm{d}}$ & $0.70(1.03)^{b, d}$ \\
\hline 4. $>80$ years & $3.23(2.51){ }^{c, e, f}$ & $1.97(1.52)^{c, e, f}$ & $1.13(1.31)^{c, e, f}$ \\
\hline$F(p) \eta^{2}$ & $489.6(<0.001) 0.02$ & $129.3(<0.001) 0.00$ & $966.0(<0.001) 0.04$ \\
\hline \multicolumn{4}{|l|}{ Gender } \\
\hline Male & $1.96(2.04)$ & 1.32 (1.39) & $0.58(0.93)$ \\
\hline Female & $2.75(2.34)$ & $2.01(1.63)$ & $0.65(1.00)$ \\
\hline$t(p) d$ & $44.7(<0.001) 0.35$ & $56.8(<0.001) 0.45$ & $8.8(<0.001) 0.07$ \\
\hline \multicolumn{4}{|l|}{ Marital status } \\
\hline 1. Married & $2.21(2.14)$ & $1.60(1.54)$ & $0.55(0.90)$ \\
\hline 2. Never married & $2.47(2.27)^{\mathrm{a}}$ & $1.67(1.55)$ & $0.71(1.03)^{\mathrm{a}}$ \\
\hline 3. Divorced & $2.62(2.31)^{b, d}$ & $1.91(1.64)^{b, d}$ & $0.61(0.92)^{b, d}$ \\
\hline 4. Widowed & $3.18(2.50)^{c, e, f}$ & $2.08(1.58)^{c, e, f}$ & $0.95(1.22)^{c, e, f}$ \\
\hline$F(p) \eta^{2}$ & $478.2(<0.001) 0.02$ & $270.3(<0.001) 0.01$ & $423.5(<0.001) 0.02$ \\
\hline \multicolumn{4}{|l|}{ Schooling } \\
\hline 1. > 12 years & $2.05(2.00)$ & $1.56(1.51)$ & $0.43(0.77)$ \\
\hline 2. $9-12$ years & $2.38(2.20)^{\mathrm{a}}$ & $1.71(1.57)^{\mathrm{a}}$ & $0.58(0.91)^{\mathrm{a}}$ \\
\hline 3. 6 - 8 years & $2.81(2.42)^{b, d}$ & $1.85(1.59)^{\mathrm{b}, \mathrm{d}}$ & $0.85(1.11)^{b, d}$ \\
\hline 4. $0-5$ years & $2.90(2.59)^{c, e, f}$ & $1.87(1.64)^{c, e}$ & $0.95(1.25)^{c, e, f}$ \\
\hline$F(p) \eta^{2}$ & $404.7(<0.001) 0.02$ & $112.8(<0.001) 0.00$ & $757.8(<0.001) 0.03$ \\
\hline \multicolumn{4}{|l|}{ Exercise level } \\
\hline 1. More than once a week & $1.89(1.88)$ & $1.45(1.47)$ & $0.39(0.70)$ \\
\hline 2. Once a week & 1.95 (1.93) & $1.48(1.49)$ & $0.42(0.73)$ \\
\hline 3. 1 to e times a month & $2.11(2.04)^{b, d}$ & $1.57(1.53)^{b, d}$ & $0.48(0.81)^{b, d}$ \\
\hline 4. Hardly ever, or never & $3.02(2.49){ }^{c, e, f}$ & $2.01(1.62)^{c, e, f}$ & $0.90(1.17)^{c, e, f}$ \\
\hline$F(p) \eta^{2}$ & $1268.3(<0.001) 0.05$ & $607.7(<0.001) 0.02$ & $1372.4(<0.001) \mathbf{0 . 0 6}$ \\
\hline \multicolumn{4}{|l|}{ Social Activities } \\
\hline Yes & 2.03 (1.95) & $1.56(1.50)$ & $0.41(0.72)$ \\
\hline No & $2.85(2.50)$ & $1.87(1.63)$ & $0.88(1.16)$ \\
\hline$t(p) d$ & $45.3(<0.001) 0.36$ & $24.3(<0.001) 0.19$ & $60.4(<0.001) 0.48$ \\
\hline \multicolumn{4}{|l|}{ Employment } \\
\hline 1. Working & $1.87(1.87)$ & $1.47(1.48)$ & $0.36(0.68)$ \\
\hline 2. Retired & $2.41(2.22)^{\mathrm{a}}$ & $1.67(1.53)^{\mathrm{a}}$ & $0.66(0.99)^{\mathrm{a}}$ \\
\hline 3. Unemployed & $2.87(2.43)$ b,d & $2.03(1.71)^{b, d}$ & $0.72(0.99)^{b, d}$ \\
\hline 4. Homemakers & $2.96(2.58)^{c, e}$ & $2.04(1.69){ }^{c, e}$ & $0.83(1.17)^{c, e, f}$ \\
\hline 5. Sick or disabled & $4.11(2.70)^{g, h, I, j}$ & $2.75(1.70)^{g, h, I, j}$ & $1.18(1.29)^{g, h, I, j}$ \\
\hline$F(p) \eta^{2}$ & $669.5(<0.001) 0.04$ & $418.7(<0.001) 0.02$ & $577.3(<0.001) 0.03$ \\
\hline \multicolumn{4}{|l|}{ Making ends meet } \\
\hline Easily & 1.85 (1.89) & $1.40(1.43)$ & $0.40(0.74)$ \\
\hline Fairly easily & $2.20(2.07)^{\mathrm{a}}$ & $1.58(1.49)^{\mathrm{a}}$ & $0.56(0.89)^{a}$ \\
\hline Some difficulty & $2.87(2.38)^{b, d}$ & $1.99(1.63)^{b, d}$ & $0.78(1.07)^{b, d}$ \\
\hline Great difficulty & $3.90(2.73)^{c, e, f}$ & $2.55(1.73)^{c, e, f}$ & $1.19(1.30)^{\text {c, e, f }}$ \\
\hline$F(p) \eta^{2}$ & $1614.2(<0.001) \mathbf{0 . 0 7}$ & $1036.4(<0.001) 0.04$ & $1235.8(<0.001) 0.06$ \\
\hline \multicolumn{4}{|l|}{ Perceived physical health } \\
\hline 1. Very good & $1.34(1.52)$ & $1.03(1.24)$ & $0.28(0.58)$ \\
\hline 2. Good & $1.93(1.82)^{\mathrm{a}}$ & $1.44(1.43)^{\mathrm{a}}$ & $0.44(0.73)^{\mathrm{a}}$ \\
\hline 3. Fair & $3.09(2.25)^{b, d}$ & $2.19(1.58)^{b, d}$ & $0.81(1.03)^{\mathrm{b}, \mathrm{d}}$ \\
\hline 4. Poor & $4.95(2.65)^{\text {c, e, f }}$ & $3.04(1.54)^{c, e, f}$ & $1.65(1.46)^{\mathrm{c}, \mathrm{e}, \mathrm{f}}$ \\
\hline$F(p) \eta^{2}$ & $6097.7(<0.001) 0.22$ & $3831.0(<0.001) \mathbf{0 . 1 5}$ & $4146.4(<0.001) 0.16$ \\
\hline
\end{tabular}

Note: $F$ = ANOVA; $t$ = Student's $t$ test; Bonferroni contrasts: ${ }^{\mathrm{a}} 1-2,{ }^{\mathrm{b}} 1-3,{ }^{\mathrm{c}} 1.4,{ }^{\mathrm{d}} 2-3,{ }^{\mathrm{e}} 2-4,{ }^{\mathrm{f}} 3-4 ;{ }^{\mathrm{g}} 1-5,{ }^{\mathrm{h}} 2-5,{ }^{\mathrm{i}} 3-5,{ }^{\mathrm{j}} 4-5$ Effect size: Eta squared $\left(\eta^{2}\right)=$ weak $(\leq 0.05)$, moderate $(0.06-0.13)$, strong $(>0.13)$; Cohen's $d(d)=$ weak $(<0.50)$, moderate (0.50-0.80), strong $(>0.80)$. Effect size moderate and strong are shown in bold.

EURO-D = Depression scale; Factor 1 = Suffering; Factor 2 = Motivation 